artigo

0 Grupo de Trabalho Moda, Sustentabilidade e Inclusão Social parece, à primeira vista, uma combinação paradoxal, visto que na moda a novidade é um valor secular e nas passarelas existe um padrão de beleza que se impõe. Como desenvolver então uma moda que aumente 0 ciclo de vida dos produtos, diminua impactos ambientais e desenvolva também produtos para deficientes físicos, idosos e obesos? Essas perguntas representam muitas outras que ocupam a sociedade contemporânea com pesquisas para o desenvolvimento sustentável e com ações para a construção de uma sociedade mais justa e inclusiva. A questão mais ampla e complexa aparece: que outros valores poderão ser adicionados aos produtos de moda sem que a moda perca seu caráter de sedução e sua vitalidade econômica?

A concepção dos produtos, sua produção, distribuição, uso e descarte precisam atender aos quesitos de desenvolvimento sustentável nos aspectos econômicos, sociais e ambientais. Palavras de ordem como reduzir, reutilizar e reciclar; atitudes como consumo consciente, produção limpa, avaliação do impacto ambiental e remuneração justa são assumidas pelo vocabulário da moda.

0 GT, iniciado em 2009, cresce incitando designers à avaliação de algumas práticas sedimentadas no sistema da moda. As expectativas de uma nova geração de consumidores preocupada, por um lado, com os impactos ambientais decorrentes da exploração desmedida do planeta e, por outro lado, com uma sociedade mais equânime que proporcione qualidade de vida e autonomia a todos são fatores que precisam ser considerados nos projetos atuais de moda.

Pesquisa e estudos comparativos - dos tecidos e fibras sustentáveis; dos processos de curtição dos couros de origem natural; das formas de lavagem do jeans; das plantações do algodão orgânico e do tradicional; dos tingimentos naturais e químicos; dos destinos dados aos resíduos têxteis; dos meios e processos de reciclagem dos materiais; das combinações da moda com 0 artesanato; das novas modelagens zero waste; dos recursos naturais como fonte de energia - têm ocupado a agenda dos pesquisadores buscando inovações para o desenvolvimento sustentável na indústria da moda.

0 artigo a seguir, apresentado no $9^{\circ}$ Colóquio de Moda por Felipe Guimarães, faz um estudo comparativo das técnicas analógicas e digitais de criação e produção de impressão têxtil, articulando o conceito de inovação tecnológica incremental, com a intenção de atender as premissas de um desenvolvimento sustentável no campo da moda.

Boa leitura e boas inspirações.

Ana Mery Sehbe De Carli e Suzana Barreto Martins 


\section{[ FELIPE GUIMARÃES ]}

Mestrando em Design pela Universidade Anhembi Morumbi, em São Paulo. Graduado em Negócios da Moda, com habilitação em Design de Moda, e especialização em Criação e Desenvolvimento de Produto de Moda pela mesma universidade. Desde 2006, atua na área Têxtil e de Moda, com foco em estamparia convencional e digital.

E-mail: talk2felipe@hotmail.com

\section{Inovações em processos de impressão têxtil'}

\section{Innovations in textile printing processes}

[resumo] 0 escopo deste artigo aborda o conceito de inovação tecnológica incremental, especificamente em relação às técnicas analógicas e digitais de criação e produção de impressão têxtil, com vistas a discutir as transformações decorrentes das questões sustentáveis de impacto global.

[abstract] The scope of this article covers the concept of incremental technological innovation, specifically in relation to analog and digital techniques for the creation and production of textile printing, aimed at discussing the transformations resulting from sustainabilityrelated issues.

[keywords] innovation; textile printing; surface design; sustainability. 
0 percurso da impressão têxtil, assim como o tingimento de substratos têxteis², envolve um passado de algumas décadas. Com suas raízes nos artesanatos antigos, manteve-se um processo tecnicamente complexo e até hoje as fábricas especializadas têm sido capazes de produzir impressões em substratos têxteis adequadamente com 0 uso de tecnologias analógicas como a serigrafia rotativa, a ser tratada posteriormente.

Na última década, a tecnologia de impressão digital mudou o panorama da indústria têxtil. Ao adaptar as tecnologias de impressão em papel, esses avanços permitiram abrir novas perspectivas aprimorando a criação e os processos de produção das etapas envolvidas em projetos de design de superfície ${ }^{3}$ - as impressões têxteis, especificamente - tais como a amostragem ${ }^{4}$, os strike-offs ${ }^{5}$, a criação e produção, os beneficiamentos, entre outras.

Dentro dessas novas perspectivas, articulam-se os processos e etapas análogas às inovações tecnológicas incrementais, consistindo na adoção de métodos de produção novos ou significativamente melhorados (OCDE, 1997), ou seja, um novo direcionamento para o processo de criação e produção na indústria têxtil.

A inovação tecnológica incremental pode se relacionar com o reconhecimento de uma demanda potencial e viabilidade técnica (baseadas na utilização atual dos recursos naturais) desses métodos de criação e produção adotados, partindo-se para a elucidação dos processos de impressões digitais têxteis a fim de investigá-los, com vistas às transformações da criação e produção em projetos de design de superfície na indústria têxtil.

\section{Impressão analógica em substratos têxteis}

Por meio de carimbos deu-se o processo de mecanização das impressões têxteis, bem como as distintas técnicas e tecnologias de gravação, e os primeiros equipamentos mecânicos de produção desenvolvidos na Inglaterra dedicaram-se a reproduzir a linguagem dos carimbos, caracterizada pela nítida separação entre as cores e pela impressão sólida ${ }^{6}$ que, com o uso da retícula ${ }^{7}$, poderia promover variedades tonais além daquelas obtidas pelo uso de distintas cores de impressão. A estética "maquínica", nesse aspecto, esteve vinculada a essa técnica até o surgimento da serigrafia, já no fim dos anos 1920 (NEIRA, 2012).

Salienta-se que, anteriormente à serigrafia, nem toda impressão era feita com carimbos ou pelo princípio revelográfico. Existiam pelo menos outras três técnicas para a execução de um processo destinado à impressão analógica em substratos têxteis (independentemente da tecnologia de produção e reprodução de desenhos) que são: o batik ${ }_{1}^{8}$ o tie-dye ${ }^{9}$ e o estêncillo (SCHOESER, 2004 e STOREY, 1974 citados por NEIRA, 2012). Porém, as técnicas mais prevalecentes de impressão na indústria têxtil são na atualidade a serigrafia rotativa e a serigrafia de mesa.

A serigrafia rotativa foi desenvolvida em meados da década de 1950. Nesse processo são utilizadas telas cilíndricas (cilindros) que giram e em contato com 0 substrato têxtil formam genuinamente uma impressão contínua. Alimentadas com corante pelo seu interior durante a impressão, essas telas expelem por meio mecânico o corante através das zonas gravadas que formam o desenho.

Das técnicas de impressões analógicas têxteis anteriormente citadas, a serigrafia rotativa tem muitas vantagens e pode ser considerada uma inovação incremental dentro da indústria têxtil, visto que são promovidos aperfeiçoamentos e melhorias dos produtos, dos equipamentos e dos métodos de fabricação (LARANJA; SIMÕES e FONTES, 1997), nos quais a impressão por cilindro oferece alta velocidade na produção e consequente vantagem econômica. Os corantes são relativamente baratos e proporcionam uma vasta gama de cores. No entanto, a grande desvantagem da serigrafia rotativa é a limitação da largura das telas cilíndricas e o comprimento de imagem que pode ser impressa (MILES, 2003).

Já a serigrafia de mesa utiliza-se de telas planas para impressão analógica nas quais as cores são decompostas pelo processo de quadricromia (CMYK) ${ }^{11}$ - sendo posicionadas ao longo da parte superior da mesa onde há uma correia, conhecida como tapete ou manta. 0 substrato têxtil é gomado nas ourelas ${ }^{12}$ junto ao tapete e assim movem-se simultaneamente de forma intermitente obedecendo à repetição do 
processo de gravação. Todas as cores do desenho são impressas enquanto o substrato têxtil está estacionado, em seguida, as telas são levantadas e o substrato têxtil move-se, mantendo a distância de uma tela e desse modo se repete todo o processo.

A impressão por serigrafia de mesa é muito mais lenta do que a rotativa, mas, da mesma forma, ambas as técnicas hoje não respondem totalmente às novas demandas de alto desempenho de criação e produção da indústria têxtil e ao que se refere às questões de impacto ambiental. Segundo Chung (2013), o setor têxtil tem por objetivo desenvolver maquinário de alto desempenho, "eco-friendly" ${ }^{13}$, promovendo baixa emissão de carbono - somando a isso a crescente conscientização global de proteção ambiental - inclusive com recursos de economia de energia, corantes e tecnologia de reciclagem de resíduos têxteis.

Diferentemente das técnicas anteriores, a tecnologia digital de impressão em substratos têxteis ampliou as possibilidades e desafios do design e do designer têxtil para essa conscientização global de impacto ambiental e sustentabilidade.

\section{Impressão digital em substratos têxteis}

As possibilidades de criação e produção pensadas para impressões digitais têxteis são potencialmente altas e contam com a utilização de equipamentos e softwares gráficos que podem minimizar etapas projetuais e o impacto ambiental. No entanto, até o momento, a utilização da tecnologia tem sido mais valorizada como uma solução para questões de mercado, como a velocidade de produção e a dimensão das demandas da indústria têxtil e até os custos de montagem de equipamentos.

No início de 1980, os primeiros softwares - vetoriais e de bitmap ${ }^{14}$ - começaram a ser utilizados para a elaboração de desenhos. Cabe ressaltar aqui que, apesar do desenvolvimento técnico, nem todas as empresas aplicaram todas essas tecnologias, uma vez que a constante atualização incremental tecnológica demanda alto grau de investimento financeiro.

Os processos de impressão digital têxtil prescindem de uma técnica específica e seu funcionamento é regido pela transmissão de dados de imagem diretamente do computador para os cabeçotes de impressão (variando em quantidade, conforme 0 equipamento), que depositam corantes ${ }^{15}$ pelo sistema ink-jet ${ }^{16}$ na forma de process colour $^{17}$, sobre o substrato têxtil (NEIRA, 2012).

A impressão em substratos têxteis também requer alguma adaptação das tecnologias de impressão analógica em termos de fixação da tinta sobre a superfície. A necessidade vem do fato de que o substrato têxtil precisa ter solidez nas cores e/ou nos corantes, resistindo à ação do ferro de passar a quente, à lavagem doméstica e comercial, à água, ao suor, ao manchamento, à fricção etc. Assim, existem dois métodos para impressão digital em substratos têxteis: impressão ink-jet indireta (por transferência de calor) e impressão ink-jet direta.

A impressão indireta por transferência de calor utiliza um papel especial acrescido de uma película plástica capaz de imprimir o desenho. Depois disso, a imagem pode ser transferida para o substrato têxtil por meio da aplicação de calor no referido papel. Como resultado dessa aplicação, a película plástica é transferida para a superfície do substrato têxtil.

Para a impressão ink-jet direta, a fixação de cor também é realizada com a aplicação de alta temperatura à superfície. Isso pode ser feito por meio de um dispositivo vaporizador ou pela transferência de calor em um forno de alta temperatura. A escolha entre um dos métodos de impressão digital ocorre com base nos componentes químicos utilizados para a impressão.

Pode-se considerar que além das vantagens econômicas e ambientais trazidas pela impressão digital têxtil, a etapa projetual também teve sua metodologia agilizada, haja vista o percurso entre desenho e produção minimizado pela eliminação da etapa de gravação. Cabe ao designer, no entanto, conhecer mais profundamente a tecnologia digital de impressão para que possa, adequadamente, preparar o desenho, ou seja, o projeto para a impressão sobre o substrato têxtil.

De forma específica, na etapa de criação e desenho, os maiores ganhos são dimensionais e cromáticos. Em termos dimensionais, a vantagem é decorrente da eli- 
minação de sistemas de repetição rígidos e, com relação aos cromáticos, verifica-se a ampliação tonal proporcionada pela simultaneidade de cores possíveis de serem usadas. Elimina-se a necessidade de se fazer a transição entre as cores por meio de retículas que diminuem a qualidade das imagens ou, ainda, a redução de cores em virtude de um número limitado de cilindros (ou quadros) de impressão.

Independentemente da significação que possa ser associada a qualquer desenho ou arte final, surgem como caracterização da impressão digital têxtil alguns pontos significativos, tais como a ausência de contato manual entre o método de impressão e o substrato têxtil; ausência de gastos com gravação da arte final em cilindros (incluindo o tempo de fabricação destes); rápida alteração da arte final, se necessário; números de cores ilimitados; capacidade de impressão direto do software. Sendo assim, parte-se para a investigação dos métodos de criação e produção das impressões analógicas e digitais têxteis com vistas às inovações tecnológicas incrementais compreendendo as vantagens e benefícios do processo digital.

\section{Alcances das inovações tecnológicas}

Nos dias atuais, a indústria têxtil transforma-se rapidamente e a única maneira para os produtores sobreviverem é acompanhar as necessidades dos clientes/usuários. Os métodos de impressão, antes do advento da tecnologia digital têxtil, não conseguiram cumprir as exigências mercadológicas (maior qualidade/quantidade de novos desenhos e número de cores ilimitado, por exemplo) e as empresas viram-se obrigadas a procurar novas maneiras de satisfazer as demandas dos clientes, minimizando os custos de produção e os resíduos poluentes. Originalmente concebida para impressão em papéis, a tecnologia de impressão ink-jeté agora utilizada no mercado têxtil com mais frequência, uma vez que atende às demandas dos processos digitais.

Essas demandas ocorrem pela necessidade da indústria têxtil em produzir menores tiragens, melhorar custos e desenvolver projetos mais rápidos e frequentes, que aumentem a demanda de personalização de produtos ${ }^{18} \mathrm{e}$, por consequência, ampliem o número de ofertas por segmento. Nesse sentido, a procura por impressão digital têxtil é crescente e tende a aumentar nos próximos anos (TIPPETT, 2012).

Como acontece em qualquer indústria, as diferentes etapas do processo de produção são influenciadas por tecnologias especificas, e a respeito da impressão digital têxtil podemos citar como as etapas de maior aproveitamento dessas tecnologias a redução do trabaIho do designer, eliminando a separação de cores e vetorização ${ }^{19}$ do desenho; diminuição do tempo necessário para adaptar e controlar os desenhos, como na criação de rapport ${ }^{20}$ no caso de desenhos corridos; facilidade na avaliação de alternativas de desenho em um substrato têxtil, como em simulações realistas; criação do desenho diretamente no software gráfico e, por fim, eliminação da gravação de cilindros, preparação de corantes, ajustes de maquinário e lavagens de cilindros ou quadros depois de utilizados (I.T. STRATEGIES, 2012).

Os resultados das inovações tecnológicas, pelo aspecto do processo de produção, são benéficos não apenas para as grandes empresas da indústria têxtil, mas também para os designers sem conhecimento técnico específico para execução de projetos de design de superficie têxtil (BOWLES e ISAAC, 2009), possibilitando a este profissional expandir suas experiências nas interfaces computacionais.

Já pelo aspecto do processo de criação, o desenvolvimento rápido nos últimos anos dos computadores, programas gráficos e periféricos a eles relacionados foram capazes de realizar com grande eficiência a maior parte do trabalho de desenho normalmente feito a lápis, caneta e pincel.

Tal produção imagética facilitada por softwares tem sido mais uma possibilidade de expansão no desenvolvimento criativo e produtivo do designer em projetos digitais têxteis que demandam constante atualização em ferramentas de auxilio para manipulação do desenho. Nessa linha, muitos desses profissionais começaram a perceber nas inovações tecnológicas incrementais outras potencialidades na criação e produção em projetos de design de superfície.

Em paralelo a esse movimento de inovações, é importante relembrar que, ao fim da década de 1920, artistas plásticos se interessaram pelo design de superfície têxtil, justamente pela liberdade advinda das novas tecnologias. Sonia Delaunay, Salvador 
Dalí, Raoul Doufy entre outros propunham estampas que foram adaptadas, por gravadores, para a indústria (SCHOESER, 1986).

Sendo assim, com vistas às inovações e a fim de compreender as vantagens da impressão digital têxtil visando às questões de sustentabilidade, é necessário ressaltar não só os problemas, mas também os diferentes métodos e processos de produção antes, durante e depois das impressões analógicas e digitais, bem como a contabilização da redução dos processos e impactos ambientais. A seguir, um quadro sequencial com o exemplo prático de uma empresa no ramo têxtil da área de estamparia que se utiliza dos dois processos de impressão.

\begin{tabular}{|c|c|c|}
\hline & PROCESSO ANALÓGICO & PROCESSO DIGITAL \\
\hline 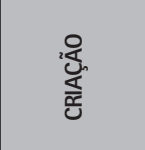 & $\begin{array}{l}\text { Briefing } \\
\text { Projeto/Desenho original } \\
\text { Layout da imagem } \\
\text { Separação de cores/Netorização } \\
\text { Gravação de cilindros ou quadros }\end{array}$ & $\begin{array}{l}\text { Briefing } \\
\text { Projeto/Desenho original } \\
\text { Layout da imagem }\end{array}$ \\
\hline 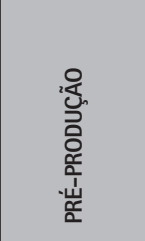 & $\begin{array}{l}\text { Posicionamento dos cilindros } \\
\text { Preparação dos corantes } \\
\text { Alimentação dos cilindros com os corantes } \\
\text { Preparação do tapete da máquina com goma } \\
\text { (que serve de adesivo ao substrato têxtil) } \\
\text { Secador é aquecido }\left(150{ }^{\circ} \mathrm{C} \text { a } 200^{\circ} \mathrm{C}\right) \\
\text { Ajuste de tela }(\cong 10 \text { metros), antecedente ao } \\
\text { substrato têxtil, para encaixe do desenho }\end{array}$ & $\begin{array}{l}\text { Ajuste da imagem (desenho), rapport, } \\
\text { dimensão e cor } \\
\text { Imagem enviada ao software RIP } \\
\text { Seleção da metragem e/ou repetição } \\
\text { que será produzida }\end{array}$ \\
\hline PRODUÇÃO & Impressão da produção & Impressão da produção \\
\hline 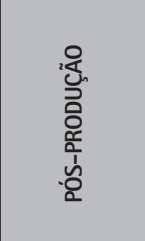 & $\begin{array}{l}\text { Secador é resfriado } \\
\text { Retirada de corantes } \\
\text { Descarte/Estocagem de corantes } \\
\text { Retirada dos cilindros } \\
\text { Lavagem dos cilindros } \\
\text { Armazenamento dos cilindros } \\
\text { Limpeza do tapete } \\
\text { Lavagem da máquina }\end{array}$ & $\begin{array}{l}\text { Autolimpeza do tapete } \\
\text { Periodicamente limpeza da cabeça de impressão }\end{array}$ \\
\hline $\begin{array}{l}\text { DADOS DO } \\
\text { MAQUINÁRIO }\end{array}$ & 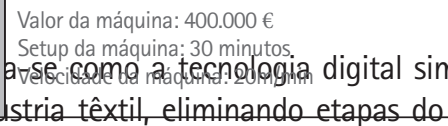 & 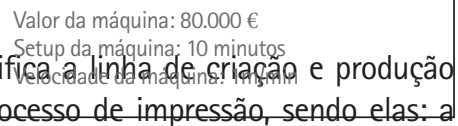 \\
\hline
\end{tabular}

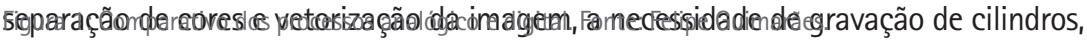
a preparação de corantes para amostras, a lavagem de cilindros ou quadros, descarte de corantes etc. Como resultado, a impressão digital têxtil torna-se um processo de criação e produção favoráveis e eficiente opção para a indústria no que se refere às questões sustentáveis de impacto global.

Além disso, a concepção e a alteração do desenho são facilitadas com sua modificação no computador e seu reenvio à impressão digital. Para a produção por meio do processo analógico é necessário que o desenho seja separado em canais (cores) que serão os cilindros, enquanto por meio do processo digital a imagem só precisa ter alta resolução no tamanho desejado. Em alguns casos, o desenho que será produzido no processo digital também será produzido no processo analógico e nesses casos a imagem deverá ser a mesma, assim a reprodução será bem próxima em ambos os processos.

0 ganho de tempo é significativo, visto que no processo analógico levaria mais tempo para ser refeito passando por todas as etapas do processo, enquanto o processo digital levaria menos tempo, apenas sendo ajustado no software. Porém, em termos de velocidade de máquina, o processo analógico ainda é mais eficiente do que o digital, por exemplo, enquanto o primeiro imprime 100 metros de substrato têxtil em 5 minutos, o segundo imprime 100 metros de substrato têxtil em 100 minutos. 
Contudo, destaca-se a oferta de benefícios do processo digital, como a eliminação de problemas decorrentes da utilização de processos analógicos já elucidados, assim como a economia de tempo - tanto de criação, na qual o designer pode apresentar modificações ou um novo desenho, quanto de produção, onde se reduzem custos,

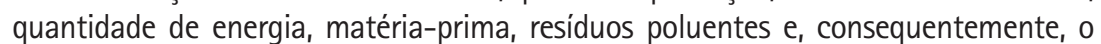
impacto ambiental, oferecendo uma opção ecologicamente mais consciente e sustentável para a indústria têxtil.

As empresas utilizam o processo analógico para grandes quantidades, algumas amostras são feitas nesse processo, mas isso é uma exceção, tendo em vista que o custo é impraticável (30 minutos de setup, carregamentos de cilindros, corantes etc.). $\mathrm{Na}$ prática, 80\% das amostras são feitas pelo processo digital, compensado pela agilidade e facilidade em produzir amostras até que os cilindros do processo analógico sejam gravados e todas as etapas da máquina estejam em ordem para a impressão têxtil.

Importante destacar que ainda hoje a procura maior é pelo processo analógico, pois atinge um maior número de empresas e certamente ainda produz um volume maior e, além disso, as indústrias têm estrutura, maquinário, pessoas e todos os insumos para o funcionamento por meio desse processo - o custo de transferir toda essa estrutura para o processo digital é elevado.

\section{Considerações finais}

Atualmente, a impressão digital têxtil apresenta-se, em termos expressivos, como a tecnologia mais revolucionária que a indústria de impressão têxtil vivenciou desde 0 surgimento da serigrafia nos anos 1950.

Inicialmente impulsionada pela necessidade de simplificar e aperfeiçoar o processo analógico de impressão de amostras, a impressão digital têxtil inovou não só esse processo, mas também diversas etapas da criação e produção, sinalizando a importância para a redução de impactos ambientais. No entanto, trata-se de uma tecnologia relativamente nova. Os clientes/usuários que a utilizam ainda a oferecem como forma de um produto ou serviço "eco-friendly" se promovendo em relação às questões sustentáveis, não sendo o foco principal a consciência da indústria têxtil sobre o impacto ambiental global.

Assim como é importante estar ciente das questões jurídicas, por exemplo, acerca da indústria têxtil, é importante considerar o seu impacto sobre o meio ambiente. A impressão têxtil, analógica ou digital, visando à preocupação com a sustentabilidade na indústria têxtil deve estar alinhada à sua própria prática diária. Os designers têxteis, que fazem parte da prática, muitas vezes estão na posição de consumidor na hora da compra e/ou escolha de materiais, equipamentos e outros recursos a fim de executar o seu trabalho. Esses recursos podem incluir gasto de energia, gasto com corante, tecido etc. (RUSSELL, 2011).

0 que se observa é que somente parte dessa potencialidade da impressão digital têxtil como forma de redução do impacto ambiental global foi experimentada até 0 momento, já que esse processo depende também do domínio dos softwares gráficos por parte dos designers têxteis e domínio panorâmico da situação da indústria têxtil. Segundo Hawken (citado por RUSSELL, 2011), a primeira regra de sustentabilidade é alinhar-se com as forças naturais, ou pelo menos não tentar desafiá-las.

De alguma forma, a sustentabilidade deve ser incorporada à indústria têxtil. Independentemente de saber se o cliente/usuário está ciente de que um determinado produto é sustentável, cabe ao designer têxtil (e não só) apontar possiveis caminhos para a utilização da impressão digital têxtil. Embora seja importante ter a boa compreensão das questões envolvidas, pode-se argumentar que tanto a indústria e o designer têxtil quanto o cliente/usuário estão conscientes dos prejuízos. Eles sabem que certas ações estão tendo um efeito negativo sobre o planeta, mas essa consciência é apenas o primeiro passo. 


\section{NOTAS}

[1] Por indicação das coordenadoras do GT Moda, Sustentabilidade e Inclusão Social, Ana Mery Sehbe De Carli e Suzana Barreto Martins, excepcionalmente, o trabalho premiado foi apresentado nas Sessões de Comunicação Oral.

${ }^{[2]} 0$ substrato têxtil corresponde ao tecido após sofrer vários processos fisicos e químicos durante os beneficiamentos, cujo objetivo é melhorar o aspecto visual e tátil do substrato têxtil, bem como a capacidade tintórea.

${ }^{[3]}$ Rütschilling (2006 citada por LEVINBOOK, 2008, p. 372) considera o design de superficie como "uma atividade técnica e criativa cujo objetivo é a criação de imagens bidimensionais (texturas visuais e táteis), projetadas especificamente para a constituição e/ou tratamento de superficies, apresentando soluções estéticas e funcionais adequadas aos diferentes materiais e processos de fabricação artesanal e industrial".

${ }^{[4]}$ Amostragem/amostra é uma fração que permite conhecer e reconhecer a qualidade antes da produção.

${ }^{[5]}$ Equivalente à amostra, porém, após o início da produção.

${ }^{[6]}$ Sólida, no sentido de chapada, com os pontos de pigmentos bem unidos.

${ }^{[7]}$ Rede formada por retas finíssimas impressas por processos ópticos e tipográficos.

${ }^{\left[{ }^{[}\right]}$É uma técnica de tingimento artesanal. Originária da Ilha de Java, na Indonésia, consiste em desenhar com cera quente sobre o substrato têxtil - que, após se partir, dá um efeito de craquelado - e em seguida tingi-lo com cores variadas.

[9] Também é uma técnica de tingimento artesanal. No tingimento os desenhos são produzidos a partir de partes do tecido protegidas do contato com o corante - o tecido é enrolado e amarrações são feitas nas partes que não devem ser tingidas.

${ }^{[10]}$ Técnica na qual o desenho é obtido por meio de aplicação de tinta em papel ou acetato cortado ou perfurado.

${ }^{[11]}$ CMYK, sigla que identifica a quadricromia, pela mistura tonal ou óptica das cores primárias, do sistema subtrativo ciano, magenta, yellow (amarelo) e key (preto).

${ }^{[12]}$ Extremidade mais grossa de um tecido, que lhe serve de acabamento no sentido do urdume (longitudinal); margem e/ou borda do tecido.

${ }^{[13]}$ Expressão em inglês, significa ecologicamente correto.

${ }^{[14]}$ Mapa de bits, sendo bit a menor parcela de informação processada por um computador.

${ }^{[15]}$ Esses pontos são depositados - por porções dos corantes em distância regular, o que permite a obtenção de um número praticamente ilimitado de cores e nuances - pelo sistema process colour, isto é, pela utilização da mistura de cores consideradas primárias para essa técnica: CMYK e adicionadas a estas O OB (orange e blue), que aumentam a gama de cores que podem ser obtidas.

${ }^{[16]}$ É um tipo de impressão de computador na qual é criada uma imagem propelindo gotículas de tinta sobre, no caso, o substrato têxtil.

[17] É o modelo de cor subtrativo usado na impressão de cores e também para descrever o processo de impressão. Refere-se aos quatro corantes: ciano, magenta, amarelo e preto (CMYK).

${ }^{[18]}$ Nesse sentido, maior variação de desenhos, maior número de amostras, maior número de cores por desenho, individualização do desenho (não há necessidade de venda casada, ou seja, a divisão da produção do desenho em dois ou mais clientes/empresas), maior repetição da produção, se necessário etc.

${ }^{[19]}$ Linguagem técnica para transformação de linhas de uma imagem em representações numéricas, em que computadores e softwares gráficos possam reconhecer essas representações.

${ }^{[20]}$ Expressão em francês, significa repetição. É o padrão mínimo do desenho a ser impresso.

\section{REFERÊNCIAS}

BOWLES, M.; ISAAC, C. Diseño y estampación textil digital. Barcelona: Blume, 2009.

CHUNG, P. Eles só crescem, inclusive por aqui. Revista Têxtil, São Paulo, n. 723, p. 16-18, jan./fev. 2013.

I.T. STRATEGIES. Unfolding the frontiers and the future of digital printing on textiles. Disponivel em: <http://www.techexchange.com/library/Unfolding $\% 20$ the $\% 20$ Frontiers $\% 20$ and $\% 20$ the $\% 20$ Future\%20of\%20Digital\%20Printing\%200n\%20Textiles.pdf>. Acesso em: 3 fev. 2014.

LARANJA, M. D.; SIMÕES, V. C.; FONTES, M. Inovação tecnológica: experiência das empresas portuguesas. Lisboa: Texto, 1997.

LEVINBOOK, M. Design de superficie têxtil. In: PIRES, D. B. (Org.). Design de moda: olhares diversos. São Paulo: Estação das Letras e Cores, 2008, p. 379-387.

MILES, L. W. C. (Org.). Textile printing. Manchester: Society of Dyers and Colourists, 2003.

NEIRA, L. G. Impressão digital, estética artesanal. Redige, Rio de Janeiro, v. 3, n. 1, p. 18-31, abr. 2012. Disponivel em: <http://www.cetiqt.senai.br/ead/redige/index.php/redige/article/ viewFile/56/211>. Acesso em: 3 fev. 2014.

OCDE [The Organisation for Economic Co-operation and Development]. Oslo manual. Paris: OECD Publications, 1997.

RUSSELL, A. The fundamentals of printed textile design. Switzerland: AVA Publishing, 2011.

SCHOESER, M. Fabrics and wallpapers: twentieth-century design. New York: E.P. Dutton, 1986.

TIPPETT, B. A defect analysis of rotary screen vs. digital textile printing. Disponivel em: $<$ http://www.techexchange.com/library/A\%20Defect $\% 20$ Analysis $\% 20$ of $\% 20$ Rotary $\% 20$ Screen\%20vs.\%20Digital\%20Textile\%20Printing.pdf>. Acesso em: 3 fev. 2014. 